\title{
The Origin of Sulfur Tolerance in Supported Platinum Catalysts: The Relationship between Structural and Catalytic Properties in Acidic and Alkaline Pt/LTL
}

\author{
J. T. M iller*,1 and D. C. Koningsberger $\dagger$ \\ *R esearch and D evelopment, A M O CO O il Company, P.O. B ox 3011, M ail Station H -9, Naperville, Illinois 60566-7011; and †D epartment of I norganic \\ Chemistry and Catalysis, U trecht U niversity, P.O. B ox 80083, 3508 TB U trecht, The N etherlands
}

Received N ovember 10, 1995; revised A pril 22, 1996; accepted A pril 23, 1996

The reactivity, structure, and sulfur tolerance is compared for platinum supported on acidic and alkaline LTL zeolite. In the absence of sulfur, EXAFS spectroscopy indicates that small metallic platinum particles of approximately 6 to 14 atoms/cluster are present. The TOF for neopentane hydrogenolysis and isomerization is ca 100 times higher on the acidic LTL due to the metalsupport interaction. Saturation of the platinum by $\mathrm{H}_{2} \mathrm{~S}$, results in the formation of surface Pt-S bonds with a bond length of $2.33 \AA$. Comparison of the EXAFS results of the sulfur poisoned catalysts, indicates that the $\mathbf{S}$ to Pt ratio is lower for platinum on the acidic zeolite. Catalytically, the initial activity (per gram) of both catalysts is greatly reduced after sulfur poisoning due to the loss of exposed platinum, however, the initial neopentane TOF s are nearly unchanged. Because of its higher TOF, the catalytic activity (per gram) of sulfur poisoned, acidic Pt/LTL is comparable to that of nonsulfur poisoned alkaline Pt/LTL. In both sulfur poisoned catalysts the neopentane isomerization selectivity increases compared to the sulfur free catalyst. Although the initial TOFs of the nonsulfur poisoned and sulfur poisoned catalysts are the same, there is a rapid loss in activity due to coke formation in the sulfur poisoned, alkaline LTL, while rate of deactivation by coke in the sulfided, acidic LTL is much lower. The increased sulfur tolerance of acidic supported noble metal catalysts appears to result primarily from the higher intrinsic TOF. In addition, because of its resistance to coke deactivation, the acidic supported sulfur tolerant catalyst is able to maintain stable catalytic activity. () 1996 A cademic Press, Inc.

\section{INTRODUCTION}

Supported noble metal catalysts are used in a large number of commercially important applications, including hydrogenation, dehydrogenation, naptha reforming, isomerization, hydrocracking, oxidation, and automotive exhaust catalysts (1). While platinum is by far the most common catalytic metal, palladium, rhodium, iridium, and ruthenium are used in certain applications. Like all catalysts, supported metal catalysts are susceptible to poison-

\footnotetext{
${ }^{1}$ A uthor to whom correspondence should be addressed.
}

ing by a variety of agents, one of the more common being sulfur. Several excellent reviews on sulfur poisoning of transition metal catalysts are available $(2,3)$. The susceptibility to poisoning by sulfur arises from the fact that there is a strong metal-sulfur chemisorption. Thus, even small amounts of sulfur present in the reactants can lead to saturation of the metal surface. The sensitivity to sulfur poisoning varies greatly with the particular application and catalyst. For example, Pt/LTL zeolite aromatization catalysts are extremely sensitive to sulfur poisoning, requiring feed sulfur levels below 0.05 ppm for adequate catalyst life (4, 5). In contrast, conventional Pt/alumina naphtha reforming catalysts operate with feed sulfur levels up to about 20 ppm (6-8), while bimetallic distillate aromatic saturation catalysts (PtPd/acidic zeolite) can tolerate up to 1000 ppm sulfur (9-12).

There is general agreement that noble metals supported on acidic supports are more sulfur tolerant than similar catalysts on non-acidic supports (9-20). For example, in the presence of $0.5 \mathrm{wt} \%$ thiophene, the steady state activity for o-xylene saturation by $\mathrm{Pd}$ in $\mathrm{HY}$ zeolite was many times higher than that for $\mathrm{Pd}$ in NaY. In addition, the sulfur tolerance decreased as the protons in $\mathrm{Pd}-\mathrm{HY}$ were neutralized by $\mathrm{Na}^{+}$ions (15). Explanations for sulfur tolerance of acidic supported metal particles are most often ascribed to the electron deficient nature of the metal resulting from the interaction with the support $(14,15,17-20)$. It is not clear, however, why electron deficient metal particles should be more sulfur tolerant. I n one study, sulfur tolerance was observed to parallel the saturation sulfur coverage which decreased with increasing support acidity. The lower surface coverage was proposed to be due to the formation of weaker metal-sulfur bonds on acidic supports (17). D espite the general agreement that metal catalysts on acidic supports are more sulfur tolerant, a clear understanding of the effects of sulfur and the roles of various catalyst properties in improving sulfur tolerance is lacking.

In this study the structure and sulfur tolerance of platinum supported on acidic and alkaline LTL zeolite is 
compared. The results indicate that there is a high surface coverage of sulfur in both catalysts with slightly less sulfur chemisorbed to Pt supported on acidic LTL. The sulfur tolerance of $\mathrm{Pt} / \mathrm{H}-\mathrm{LTL}$ results from its inherently higher TO F and the resistance to coke deactivation.

\section{EXPE RIMENTAL}

\section{Sample Preparation}

The $\mathrm{K}-\mathrm{LTL}$ zeolite (U OP) was converted into the $\mathrm{NH}_{4}^{+}$ form by aqueous ion exchange with ten fold excess $1.5 \mathrm{M}$ $\mathrm{NH}_{4} \mathrm{NO}_{3}$ at $60^{\circ} \mathrm{C}$ for $2 \mathrm{~h}$. The zeolite was filtered, washed, and calcined at $540^{\circ} \mathrm{C}$ for $3 \mathrm{~h}$. The elemental analysis for K -LTL were 14.0 and 8.3 wt\% for $K$ and A I, respectively (K/A I molar ratio of 1.16). The elemental analysis for $\mathrm{H}-\mathrm{LTL}$ were 7.3 and 10.9 wt\%, for $\mathrm{K}$ and $\mathrm{AI}$ (K/A I molar ratio of 0.46 ).

A fter zeolites had been calcined, the zeolite supports were impregated to $1.0 \mathrm{wt} \%$ Pt by contact with tetraammine platinum nitrate (Johnson $\mathrm{M}$ atthey) in $\mathrm{H}_{2} \mathrm{O}$. The resultant slurry was allowed to stand at room temperature for $3 \mathrm{~h}$, after which it was dried at $120^{\circ} \mathrm{C}$ overnight. The crystallites of zeolite were held together without a binder. Ten grams of catalyst was reduced in $200 \mathrm{cc} / \mathrm{min}$ hydrogen by heating from room temperature to $250^{\circ} \mathrm{C}$ at $10^{\circ} \mathrm{C} / \mathrm{min}$. The catalyst was cooled in hydrogen and purged with $\mathrm{N}_{2}$ at room temperature. Five grams of the reduced catalyst was again heated to $250^{\circ} \mathrm{C}$ in $\mathrm{H}_{2}$. The $\mathrm{H}_{2}$ was switched to $\mathrm{H}_{2}$ with 500 ppm $\mathrm{H}_{2} \mathrm{~S}$ until $\mathrm{H}_{2} \mathrm{~S}$ was detected at the reactor outlet (ca $15 \mathrm{~min}$ ) with lead acetate paper. The $\mathrm{H}_{2} \mathrm{~S}$ flow was continued for $30 \mathrm{~min}$ after which the flow was returned to $\mathrm{H}_{2}$ for 30 min.

\section{EXAFS}

$D$ ata collection. The EXA FS measurements were made at the Synchrotron Radiation Source in Daresbury, UK, Wiggler Station 9.2, using a Si (220) double crystal monochromator. The storage ring was operated with an electron energy of $2 \mathrm{G} \mathrm{eV}$ and a current between 200 and $300 \mathrm{~mA}$. A t the Pt $L_{\text {III }}$ edge ( $11564 \mathrm{eV}$ ), the estimated resolution was $3 \mathrm{eV}$. The monochromator was detuned to $50 \%$ intensity to avoid the effects of higher harmonics present in the $X$-ray beam. The measurements were done in the transmission mode. $D$ ata were collect in a k-scan mode with a 5-s data acquisition at $15 \mathrm{k}$.

Samples were pressed into a self-supporting wafers (calculated to have an absorbance of 2.5) and placed in a controlled atmosphere cell (21). The samples were reduced in situ at $250^{\circ} \mathrm{C}$ in flowing, prepurified, dry $\mathrm{H}_{2}$ at $1 \mathrm{~atm}$. $\mathrm{D}$ ata were collected at liquid nitrogen temperature in the presence of $\mathrm{H}_{2}$.

$D$ ata reduction. Standard procedures were used to extract the EXAFS data from the measured absorption spectra. The preedge background was approximated by a modified V ictoreen curve (22), normalization was done by dividing the height of the absorption edge and the background was subtracted using cubic spline routines (23). The EXAFS data analysis was performed on the isolated part of the data obtained by an inverse Fourier transformation over a selected range in $r$ space.

R eference data. D Data for the phase shifts and backscattering amplitudes were obtained from EXAFS measurements of reference compounds (24). Pt foil was used for the Pt-Pt interactions, $\mathrm{Na}_{2} \mathrm{Pt}(\mathrm{OH})_{6}$ for the $\mathrm{Pt}-\mathrm{O}$ interaction and $\mathrm{H}_{2} \mathrm{PtCl}_{6}$ for the Pt-S interactions.

Data analysis. To reliably determine the parameters characterizing the high $\mathrm{Z}(\mathrm{Pt})$ and low $\mathrm{Z}(\mathrm{O}, \mathrm{S})$ contributions, multiple-shell fitting in $\mathrm{k}$ - and $\mathrm{r}$-space was done, with application of $\mathrm{k}^{1}$ and $\mathrm{k}^{3}$ weighting. The use of both $\mathrm{k}^{1}$ and $\mathrm{k}^{3}$ weighting is a prerequisite since the $\mathrm{k}$-dependence of the backscattering amplitude of the low $\mathrm{Z}$ elements is different fom the high $Z$ elements. The backscattering amplitude of the low $Z$ elements becomes very small above $k=10 A^{\circ}$, in comparison with the amplitude of the high $Z$ scatterers, which is still significant at higer values of $k$ (25). A pplication of only $k^{3}$ weighting in systems containing both high and low $Z$ scatters leads to underestimation of the low $Z$ elements. I $n$ addition, optimizing $\mathrm{k}^{1}$ and $\mathrm{k}^{3}$ fits both in $\mathrm{k}$ - and in $\mathrm{r}$-space results in a better decoupling of $\mathrm{N}$ (coordination number) and $\Delta \sigma^{2}$ (D ebye-Waller factor) as well as $\mathrm{R}$ (coordination distance) and $\Delta \mathrm{E}_{0}$ (inner potential correction), and, therefore, leads to a more reliable set of parameters (24). Further optimization of the fit was done by applying the difference file technique and phase- and amplitude-corrected Fourier transforms (26).

The errors in the structural parameters were calculated from the covariance matrix taking into account the statistical noise of the EXA FS data and the correlations between the different coordination parameters. Systematic errors are not included in the calculation of standard deviations. The amplitude of the noise was estimated from the raw data at $k$ values, where the EXAFS signal was sufficiently damped out. The values of the coodness of fit $\left(\varepsilon_{v}^{2}\right)$ were calculated as outlined in the R eports on Standards and C riteria in XA F S Spectroscopy (27).

\section{N eopentane H ydrogenolysis/I somerization}

The conversion of neopentane was conducted at $400^{\circ} \mathrm{C}$ and atmospheric pressure in a fixed-bed reactor using 1.0 vol\% neopentane in $\mathrm{H}_{2}$. C atalyst powders were pressed into wafers and crushed to 42-80 mesh particles. The catalyst loadings were approximately $0.05 \mathrm{~g}$ diluted with $2 \mathrm{~g}$ $\alpha-\mathrm{Al}_{2} \mathrm{O}_{3}$ of the same particle size. For the most active catalyst, $\mathrm{Pt} / \mathrm{H}-\mathrm{LTL}$, fine powders (less than 150 mesh) of catalyst and $\gamma-\mathrm{Al}_{2} \mathrm{O}_{3}$ (1:5 wt ratio) were well mixed, pressed into wafers, and crushed to $42-80$ mesh. The catalysts were 
prereduced at the reaction temperature for $1 \mathrm{~h}$, and the conversion was adjusted from 0.5 to $2.0 \%$ by varying the space velocity. A t each space velocity, the conversion was measured as a function of time. The initial conversion and selectivity were determine by extrapolation to time zero. The TOF (at time zero) was calculated based on the volumetric hydrogen and $\mathrm{CO}$ chemisorption and is reported as molecules/s/surface Pt atom. The selectivity is calculated on a molar basis as the percent of neopentane converted to isopentane (isomerization) and isobutane plus methane (hydrogenolysis) extrapolated to zero conversion and deactivation.

\section{RESULTS}

\section{EXAFS D ata A nalysis}

The EXAFS data (average of three scans) for Pt/H -LTL and $P t / K-L T L$, with and without sulfur, are shown in Figs. 1a and $1 b$, respectively. The signal-to-noise ratio for the average data of $\mathrm{Pt} / \mathrm{H}-\mathrm{LTL}$ is 40 at $4 \mathrm{~A}^{\circ}-1$, indicating that the data quality is sufficient to allow for a detailed EXA FS analysis. The EXAFS data for Pt/H-LTL in Fig. la (solid line) are characteristic for metallic platinum reduced at low temperature. The amplitude of the EXAFS between about $k=2$ and $6 A^{\circ}-1$ is influenced by low $Z$ neighbors, for example
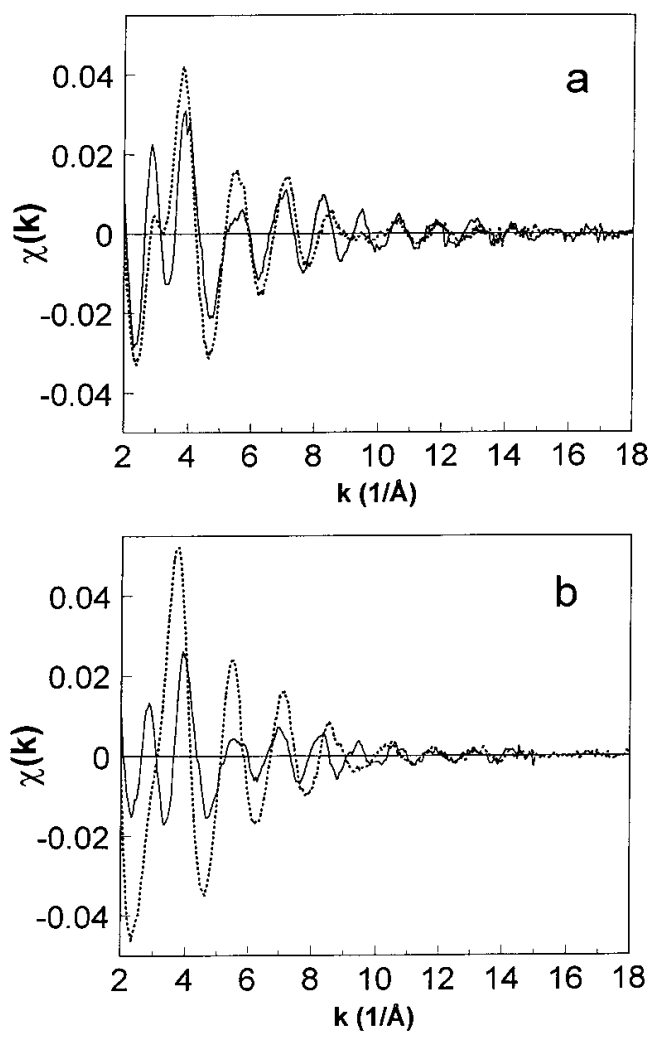

FIG. 1. EXA FS spectra of (a) Pt/H -LTL (solid line) and Pt(S)/H -LTL (dotted line), and (b) Pt/K -LTL (solid line) and Pt(S)/K -LTL (dotted line).
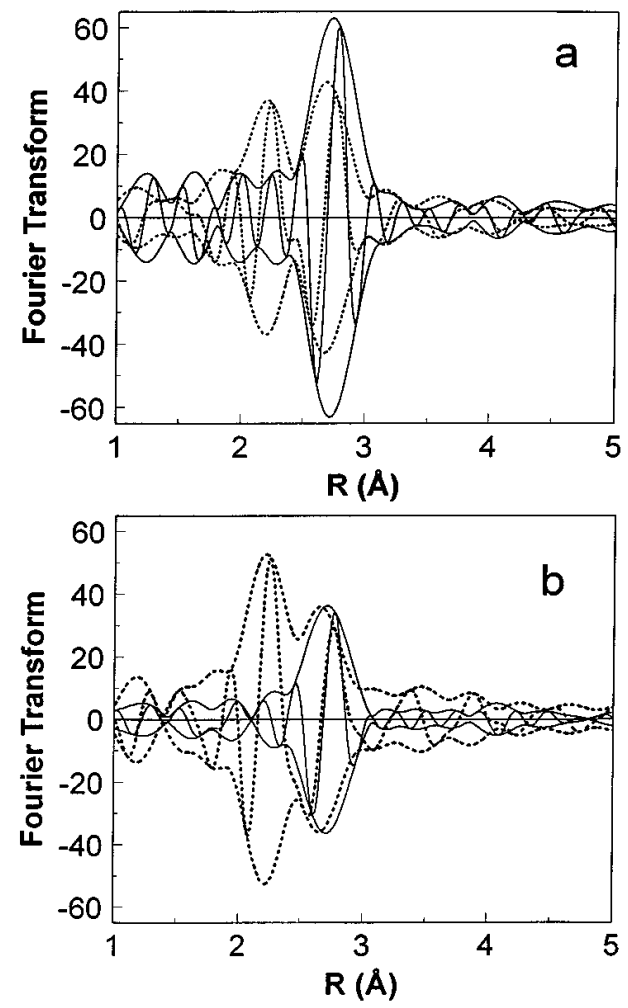

FIG . 2. Fourier transforms $\left(\mathrm{k}^{3}, \Delta \mathrm{k}=3.2-13.5 \AA^{\circ}-1, \mathrm{Pt}-\mathrm{Pt}\right.$ phase and amplitude corrected) for (a) Pt/H -LTL (solid line) and Pt(S)/K -LTL (dotted line), and (b) Pt/K -LTL (solid line) and Pt(S)/K -LTL (dotted line).

oxygen ions from the support (28). The amplitude of the signal at high values of $k$ is characteristic of metallic platinum. The dominating influence of sulfur in $\mathrm{Pt}(\mathrm{S}) / \mathrm{H}-\mathrm{LTL}$, Fig. la (dotted line), can clearly be seen from low $k$ values up to about $k=10 \mathrm{~A}^{-1}$ with a beating node at ca $9.5 \AA^{\circ}-1$. The characteristic features present in Fig. $1 \mathrm{~b}$ are similar to those in Fig. 1a except that the amplitude of the Pt-Pt contribution is smaller in Pt/K -LTL than Pt/H -LTL; compare, for example, Figs. $1 a$ and $1 b$ (solid lines). The influence of sulfur is larger in $\mathrm{Pt}(\mathrm{S}) / \mathrm{K}-\mathrm{LTL}$ than $\mathrm{Pt}(\mathrm{S}) / \mathrm{H}-\mathrm{LTL}$; compare Figs. $1 \mathrm{a}$ and $\mathrm{lb}$ (dotted lines) for $\mathrm{k}$ values between about 2 and 6 , for example.

The Fourier transforms $\left(\mathrm{k}^{3}, \Delta \mathrm{k}=3.2\right.$ to $13.5 \AA^{\circ}-1$, Pt-Pt phase and amplitude corrected) of the catalysts with and without sulfur are presented in Fig. 2. The peak at around $2.7 A^{\circ}$ is due the first coordination shell of metallic platinum and is present in all samples. Comparison of amplitudes of the Pt-Pt peak around $2.7 \mathrm{~A}$ with and without sulfur indicates that for both catalysts the amplitude of the first shell platinum peak decreases on exposure to sulfur. In addition in the sulfur poisoned catalysts there is an additional scatterer at about $2.2 \AA^{\circ}$, which will be shown below to be due to the presence of sulfur.

The normalized $\mathrm{k}^{1}$ weighted Fourier transform (Pt-Pt phase and amplitude corrected) of the EXAFS data for 

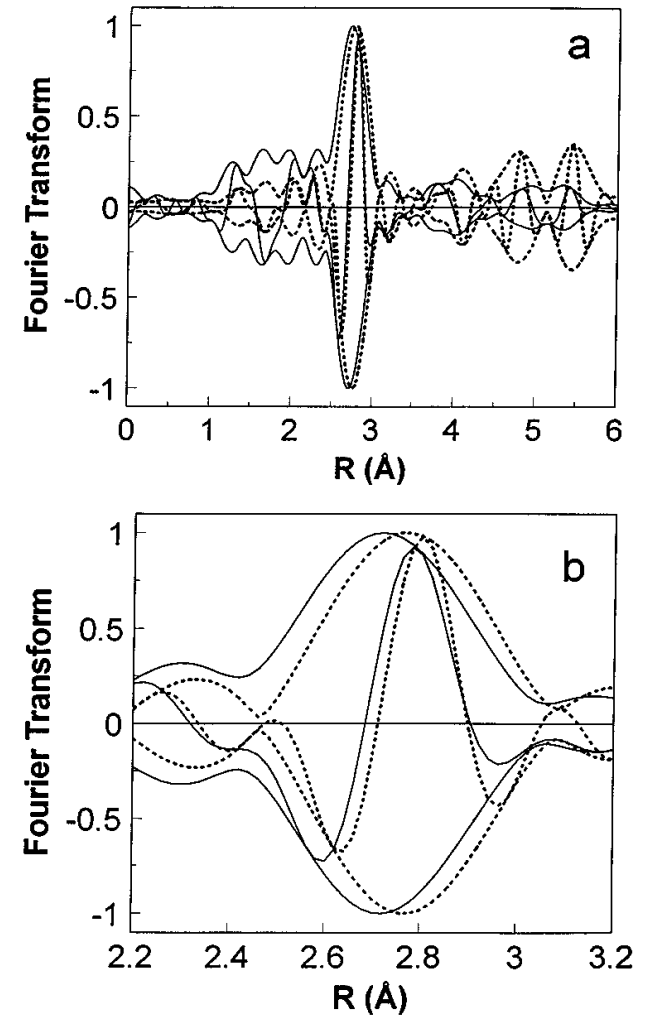

FIG. 3. Normalized Fourier transform $\left(\mathrm{k}^{1}, \Delta \mathrm{k}=3.2-13.5 \mathrm{~A}^{-1}, \mathrm{Pt}-\mathrm{Pt}\right.$ phase and amplitude corrected) for (a) Pt/H -LTL (solid line) and Pt foil (dotted line), and (b) an expanded view of 3a between $R=2.2-3.2 \AA^{\circ}$.

Pt/H -LTL and Pt foil are shown in Fig. 3. The Fourier transforms are normalized to facilitate comparison between the Pt foil and the catalyst. The near absence of higher Pt-Pt coordination shells (at $3.92,4.80$, and $5.54 \mathrm{~A}^{\circ}$ ) in the catalyst indicates that the platinum particles are small and reside within the zeolite pores (29). The particles are sufficiently small to detect contributions arising from the zeolite surface. Figure 3 is $k^{1}$ weighted in order to emphasize these low $Z$ contributions, i.e., support oxygens. E vidence for this contribution can be seen more clearly in Fig. $3 b$ which is an expansion of Fig. 3a from $r=2.2$ to $3.2 A^{\circ}$. In Fig. 3b, the node position in the imaginary part of the Fourier transforms is identical for both the Pt foil and the catalyst at $2.9 \AA^{\circ}$. The node in the imaginary part for the catalyst around $2.7 \mathrm{~A}^{\circ}$, however, is shifted to lower R. Furthermore, the imaginary parts of the Fourier transforms between about 2.2 to $2.6 \mathrm{~A}$ are completely different for the foil and the catalyst. These differences in the Fourier transforms indicate the presence of an additional oxygen scatter in the $\mathrm{Pt} / \mathrm{H}-\mathrm{LTL}$ catalyst (28).

Figure 4 shows a comparison of the Fourier transforms (Pt-Pt phase and amplitude corrected) for Pt(S)/H -LTL and $\mathrm{Pt}(\mathrm{S}) / \mathrm{K}-\mathrm{LTL}$ catalysts. A s discussed above, the peak around $2.2 \mathrm{~A}^{\circ}$ (FT is not Pt-S phase corrected) is due to the Pt-S interaction and the peak around $2.7 \mathrm{~A}$ is due to

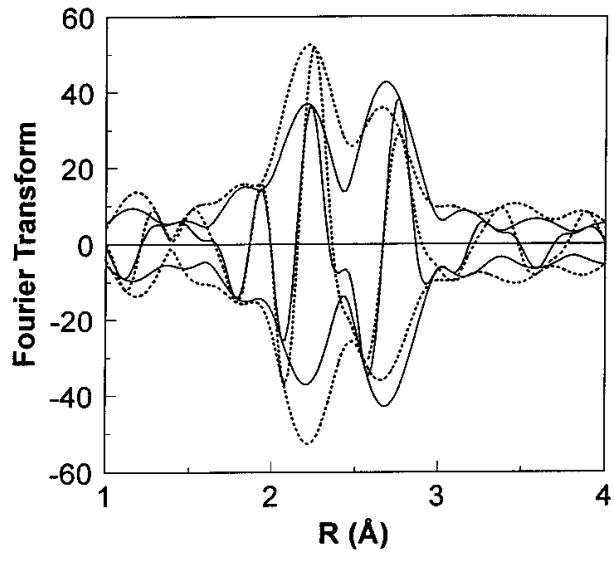

FIG . 4. Fourier transform $\left(\mathrm{k}^{1}, \Delta \mathrm{k}=3.2-13.5 \AA^{\circ}-1, \mathrm{Pt}-\mathrm{Pt}\right.$ phase and amplitude corrected) for Pt(S)/H -LTL (solid line) and Pt(S)/K -LTL (dotted line).

the first shell Pt-Pt coordination. The peak characteristic for the Pt-S is larger in Pt(S)/K - LTL whereas the amplitude of the peak characteristic for Pt-Pt first shell coordination is slightly lower in $\mathrm{Pt}(\mathrm{S}) / \mathrm{K}-\mathrm{LTL}$. H owever, there is a strong overlap of the $\mathrm{Pt}-\mathrm{S}$ and $\mathrm{Pt}-\mathrm{Pt}$ peaks. A sa result there is a contribution from the Pt-S beneath the Pt-Pt peak. Since the intensity of the $\mathrm{Pt}-\mathrm{S}$ peak is larger in $\mathrm{Pt}(\mathrm{S}) / \mathrm{K}-\mathrm{LTL}$ there is a larger Pt-S contribution to the Pt-Pt peak in this catalyst. A Ithough the amplitude of the Pt-Pt peak in the Fourier transform of $\mathrm{Pt}(\mathrm{S}) / \mathrm{K}-\mathrm{LTL}$ is only slightly smaller than that in $\mathrm{Pt}(\mathrm{S}) / \mathrm{H}-\mathrm{LTL}$, the larger contribution of the $\mathrm{Pt}-\mathrm{S}$ in $\mathrm{Pt}(\mathrm{S}) / \mathrm{K}-\mathrm{LTL}$ implies that the actual platinum particle size is smaller.

\section{EXAFS M ultiple Shell Fitting}

M ultiple shell fitting was conducted in k-space on Fourier filtered data. Fourier filtering was performed by forward Fourier transformation on $\mathrm{k}^{2}$ (or $\mathrm{k}^{3}$ for sulfided catalysts) weighted EXAFS data in order to minimize side lobes and peak widths resulting in a better separation of the EXAFS data from the background. The $k$ range was selected to give the maximum range of reliable data with $\mathrm{k}_{\min }$ and $\mathrm{k}_{\max }$ taken at node positions (22). The inverse Fourier tranform range was selected to isolate the first shell coordination sphere of platinum. B ecause multiple electron excitations dominate the Fourier transform below about $1.5 \AA$ at about this value. The ranges of Fourier filtering for each catalyst are listed in Table 1 . The number of independent parameters allowed for the model fit was determined from these ranges according to the $N$ yquist theorem (27) and are also listed in Table 1.

The results of the multiple shell fitting in $k$-space $\left(k^{1}\right.$ weighting) are given in Table 2. For both $\mathrm{Pt} / \mathrm{H}-\mathrm{LTL}$ and $\mathrm{Pt} / \mathrm{K}$-LTL the EXA FS can be fit with two significant contributions $\left(\mathrm{N}_{\text {fit }}=8\right)$ : a Pt-Pt coordination at $2.74 \mathrm{~A}^{\circ}$ and a Pt-O coordination ca $2.7 \AA$. The goodness of fit values $(0.7$ and 
TABLE 1

Fourier Filtering and Analysis R anges of the EXAFS Model Fit ${ }^{a}$

\begin{tabular}{lcccccccc}
\hline \multicolumn{1}{c}{ Catalyst } & $\mathrm{k}^{\mathrm{n}}$ & $\Delta \mathrm{k}\left(\AA^{\circ}-1\right)$ & $\Delta \mathrm{R}\left(\mathrm{A}^{\circ}\right)$ & $\Delta \mathrm{K}_{\text {anal }}\left(\AA^{\circ}-1\right)$ & $\mathrm{N}_{\text {ind }} \mathrm{b}^{\mathrm{c}}$ & $v^{\mathrm{c}}$ & Noise & $\varepsilon_{v}^{2 \mathrm{~d}}$ \\
\hline $\mathrm{Pt} / \mathrm{H}-\mathrm{LTL}$ & 2 & $2.7-14.6$ & $1.6-3.3$ & $3.6-13.5$ & 11.1 & 3.1 & 0.0015 & 0.7 \\
$\mathrm{Pt}(\mathrm{S}) / \mathrm{H}-\mathrm{LTL}$ & 3 & $2.9-13.8$ & $1.3-3.5$ & $3.5-13.5$ & 13.7 & 1.7 & 0.0015 & 0.4 \\
$\mathrm{Pt} / \mathrm{K}-\mathrm{LTL}$ & 2 & $2.6-14.0$ & $1.6-3.3$ & $3.6-13.0$ & 11.2 & 3.2 & 0.0010 & 0.9 \\
$\mathrm{Pt}(\mathrm{S}) / \mathrm{K}-\mathrm{LTL}$ & 3 & $2.0-13.6$ & $1.4-3.3$ & $3.2-13.5$ & 13.7 & 1.7 & 0.0015 & 8.5 \\
\hline
\end{tabular}

${ }^{\text {a }}$ A II model fits used a $k^{1}$ weighting.

${ }^{\mathrm{b}} \mathrm{N}_{\text {ind }}$ is the number of independent fitting parameters, $\mathrm{N}_{\text {ind }}=2 \Delta \mathrm{k} \Delta \mathrm{R} / \pi+1$.

${ }^{c} v$ is the degrees of freedom, $v=\mathrm{N}_{\text {ind }}-\mathrm{N}_{\text {fit }}$.

${ }^{\mathrm{d}} \varepsilon_{v}^{2}$ is the goodness of fit, see the R eport on Standards and Criteria (27).

0.9, for $\mathrm{Pt} / \mathrm{H}-\mathrm{LTL}$ and $\mathrm{Pt} / \mathrm{K}-\mathrm{LTL}$, respectively) are given in Table 1. The quality of the fits is similar to those previously reported (28). For Pt/H -LTL, the Pt-Pt coordination number is 5.6 (ca 14 atoms/cluster), whereas the Pt-Pt coordination number is 4.0 (ca 6 atoms/cluster) for Pt/K $-L T L$. A long Pt-O distance around $2.7 \mathrm{~A}$ is characteristic of platinum catalysts reduced at low temperature and is due to the presence of chemisorbed hydrogen between the metal cluster and the support surface $(28,30,31)$. B ecause of the smaller platinum particle size in $\mathrm{Pt} / \mathrm{K}-\mathrm{LTL}$, there is a larger Pt-O coordination number, e.g., $N=0.9$ for Pt/K -LTL compared to $\mathrm{N}=0.5$ for $\mathrm{Pt} / \mathrm{H}-\mathrm{LTL}$.

The results of the fit for $\mathrm{Pt}(\mathrm{S}) / \mathrm{H}-\mathrm{LTL}$ in $\mathrm{k}$ - and $\mathrm{r}$-space are presented in Fig. 5 with the coordination parameters given in Table 2. Similar quality fits were obtained for the other catalysts. For both $\mathrm{Pt}(\mathrm{S}) / \mathrm{H}-\mathrm{LTL}$ and $\mathrm{Pt}(\mathrm{S}) / \mathrm{K}-\mathrm{LTL}$ the EXAFS can be fit with three significant contributions $\left(\mathrm{N}_{\text {fit }}=12\right)$ : a Pt-Pt, a Pt- 0 , and a Pt-S coordination. The goodness of fit values are 0.4 for $P t(S) / H-L T L$ and 8.5 for

\section{TABLE 2}

\section{EXAFS Model C oordination Parameters ${ }^{a}$}

\begin{tabular}{lcccr}
\hline $\begin{array}{l}\text { Backscatter } \\
\text { Catalyst }\end{array}$ & $\mathrm{N}$ & $\mathrm{R}\left(\mathrm{A}^{\circ}\right)$ & $\Delta \sigma^{2}\left(\mathrm{~A}^{2}\right)$ & $\varepsilon_{0}(\mathrm{eV})$ \\
\hline $\mathrm{Pt}-\mathrm{Pt}$ & & & & \\
$\mathrm{Pt} / \mathrm{H}-\mathrm{LTL}$ & $5.5(4)$ & $2.741(4)$ & $0.0028(4)$ & $5(1)$ \\
$\mathrm{Pt}(\mathrm{S}) / \mathrm{H}-\mathrm{LTL}$ & $4.8(8)$ & $2.711(5)$ & $0.006(1)$ & $7(1)$ \\
$\mathrm{Pt} / \mathrm{K}-\mathrm{LTL}$ & $4.0(3)$ & $2.740(6)$ & $0.0042(5)$ & $5(1)$ \\
$\mathrm{Pt}(\mathrm{S}) / \mathrm{K}-\mathrm{LTL}$ & $3.3(6)$ & $2.710(9)$ & $0.008(1)$ & $5(1)$ \\
$\mathrm{Pt}-\mathrm{O}$ & & & & \\
$\mathrm{Pt} / \mathrm{H}-\mathrm{LTL}$ & $0.7(2)$ & $2.66(4)$ & $0.004(7)$ & $1(4)$ \\
$\mathrm{Pt}(\mathrm{S}) / \mathrm{H}-\mathrm{LTL}$ & $0.3(1)$ & $2.18(9)$ & $0.002(10)$ & $-7(8)$ \\
$\mathrm{Pt} / \mathrm{K}-\mathrm{LTL}$ & $0.9(2)$ & $2.70(3)$ & $0.008(5)$ & $-1(3)$ \\
$\mathrm{Pt}(\mathrm{S}) / \mathrm{K}-\mathrm{LTL}$ & $0.5(1)$ & $2.20(4)$ & $0.001(5)$ & $-3(4)$ \\
$\mathrm{Pt}-\mathrm{S}$ & & & & \\
$\mathrm{Pt}(\mathrm{S}) / \mathrm{H}-\mathrm{LTL}$ & $1.2(2)$ & $2.32(1)$ & $0.000(1)$ & $-3(2)$ \\
$\mathrm{Pt}(\mathrm{S}) / \mathrm{K}-\mathrm{LTL}$ & $1.9(2)$ & $2.33(1)$ & $0.000(1)$ & $-1(1)$ \\
\hline
\end{tabular}

\footnotetext{
a Values in brackets are the calculated limits of accuracy in the last reported digit.
}

$\mathrm{Pt}(\mathrm{S}) / \mathrm{K}$-LTL (Table 1). For both Pt(S)/H - LTL and Pt(S)/K LTL the Pt-Pt coordination number and distance decreases slightly compared to the sulfur free catalysts. For example, the Pt-Pt coordination distance decreases from 2.74 to $2.71 \AA$ and the Pt-Pt coordination number decreases from 5.5 to 4.9 for the Pt/H -LTL catalysts after sulfur poisoning. The isolated Pt-S contribution for $\mathrm{Pt}(\mathrm{S}) / \mathrm{H}-\mathrm{LTL}$ is given in Fig. 6a. The Pt-S phase corrected Fourier transform shows a Pt-S coordination distance at $2.33 \AA^{\circ}$. A similar Pt$S$ peak, but with increased amplitude, is observed for the
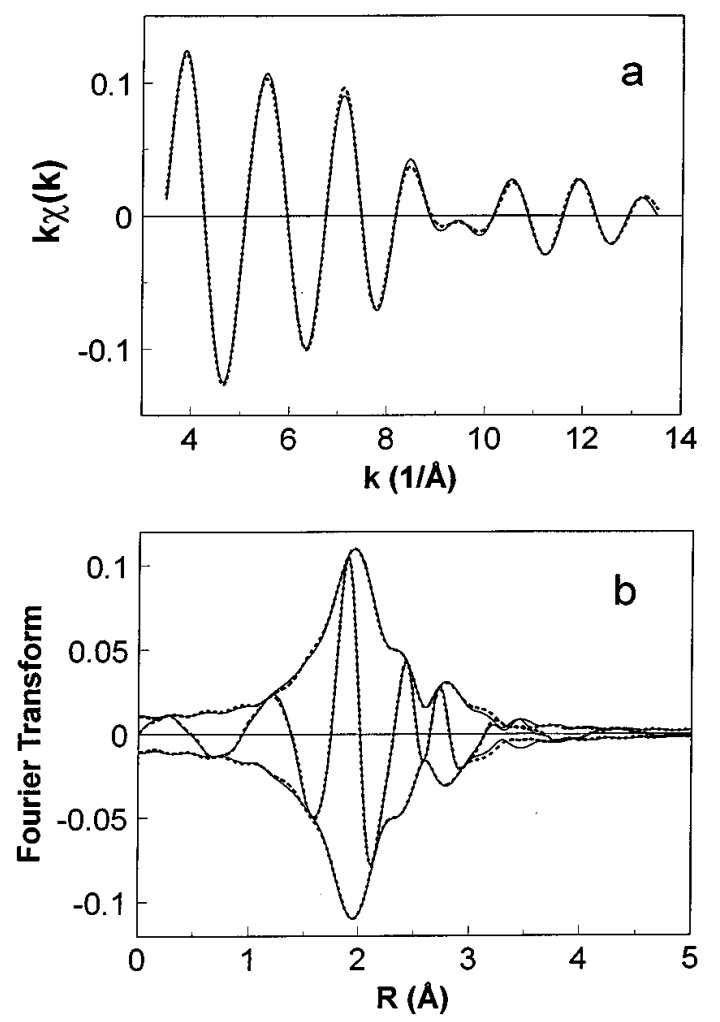

FIG . 5. R esults of the EXA FS analysis for Pt(S)/H -LTL . (a) I solated EXA FS (solid line) and the model EXA FS spectrum calculated from the parameters in Table 2 (dotted line), (b) Fourier transform $\left(\mathrm{k}^{1}, \Delta \mathrm{k}=3.5\right.$ $13.5 \mathrm{~A}^{-1}$ ) of spectra in 5 a. 

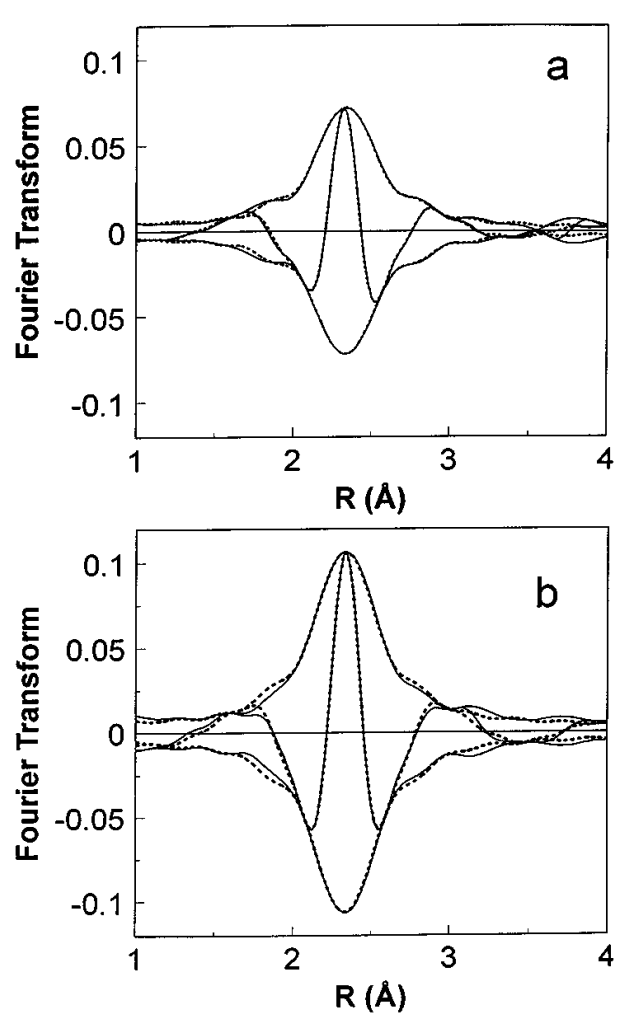

FIG . 6. The Fourier transform $\left(\mathrm{K}^{1}, \Delta \mathrm{k}=3.5-13.5 \AA^{\circ}-1, \mathrm{Pt}-\mathrm{S}\right.$ phase corrected) of the (EXAFS data- (Pt-Pt + Pt-O contributions)) (solid line) and the model fit of the Pt-S contribution (dotted line) calculated from the parameters in Table 2. (a) Pt(S)/H -LTL and (b) Pt(S)/K -LTL.

$\mathrm{Pt}(\mathrm{S}) / \mathrm{K}$-LTL catalyst, Fig. 6b. The Pt-O coordination distance for the sulfur poisoned catalysts is much smaller than that of the sulfur free catalysts. For example, in $\mathrm{Pt} / \mathrm{H}-\mathrm{LTL}$ the $\mathrm{Pt}-\mathrm{O}$ coordination distance decreases from 2.66 to $2.18 \AA^{\circ}$ upon exposure to sulfur. A Pt-O distance around $2.2 \AA$ is characteristic of platinum atoms in direct contact with the support $(28,30,31)$. The isolated Pt-O contributions for $\mathrm{Pt} / \mathrm{H}-\mathrm{LTL}$ and $\mathrm{Pt}(\mathrm{S}) / \mathrm{H}-\mathrm{LTL}$ are given in Figs. $7 \mathrm{a}$ and $7 \mathrm{~b}$, respectively. The differences in peak positions can clearly be seen.

\section{Catalytic R eaction of $\mathrm{N}$ eopentane}

A nalysis of the reaction products of neopentane at conversions between 0.5 and $2.0 \%$ by the Delplot method (32) indicate that methane, isobutane (hydrogenolysis), and isopentane (isomerization) are primary reaction products. For Pt/K -LTL and Pt(S)/H -LTL there was no deactivation; however, significant deactivation occurs for Pt/H -LTL and $\mathrm{Pt}(\mathrm{S}) / \mathrm{K}-\mathrm{LTL}$. For the latter two, the decrease in conversion with increasing time on stream was determined at constant space velocity. The In (total conversion) versus time is linear and could be extrapolated to zero deactivation, i.e., zero time on stream, Fig. 8a. Similarly, the In (selective conversion) for hydrogenolysis and isomerization versus time were linear, Fig. 8b. The selectivities were extrapolated to time zero to obtain the deactivation-free selectivity at that conversion. For example, in Fig. 8 the initial conversion is $1.49 \%$, and the initial isomerization selectivity is 0.42 . For Pt/H - LTL and Pt(S)/K -LTL, the initial conversion (zero time on stream) and selectivities were determined at several conversion levels. These initial conversions and selectivities were extrapolated to zero conversion to obtain the selectivity at zero conversion and zero deactivation. These initial catalyst selectivities and deactivation-free TO F s are given in Table 3.

A spreviously observed $(30,32,33)$, the TOF for neopentane conversion by $\mathrm{Pt} / \mathrm{H}-\mathrm{LTL}$ is much higher, approximately 150 times, based on $\mathrm{CO}$ chemisorption (90 times higher, based on $\mathrm{H}_{2}$ chemisorption) than that of $\mathrm{Pt} / \mathrm{K}-\mathrm{LTL}$. In addition, the isomerization selectivity of $P t / K-L T L$ is 0.39 , slightly higher than that of Pt/H -LTL, 0.35.

Poisoning of Pt/K -LTL by sulfur results in a large decrease in the absolute activity per gram of catalyst. The relative activity (per gram) of $\mathrm{Pt}(\mathrm{S}) / \mathrm{K}-\mathrm{LTL}$ compared to $\mathrm{Pt} / \mathrm{K}-\mathrm{LTL}$ (defined to have a relative activity of 1.0 ) is also given in Table 3. Sulfur poisoning leads to a relative activity of 0.09 for $P t(S) / K-L T L$. By contrast, the TOF of $\mathrm{Pt}(\mathrm{S}) / \mathrm{K}-\mathrm{LTL}$ is not very different from that of $\mathrm{Pt} / \mathrm{K}-\mathrm{LTL}$,
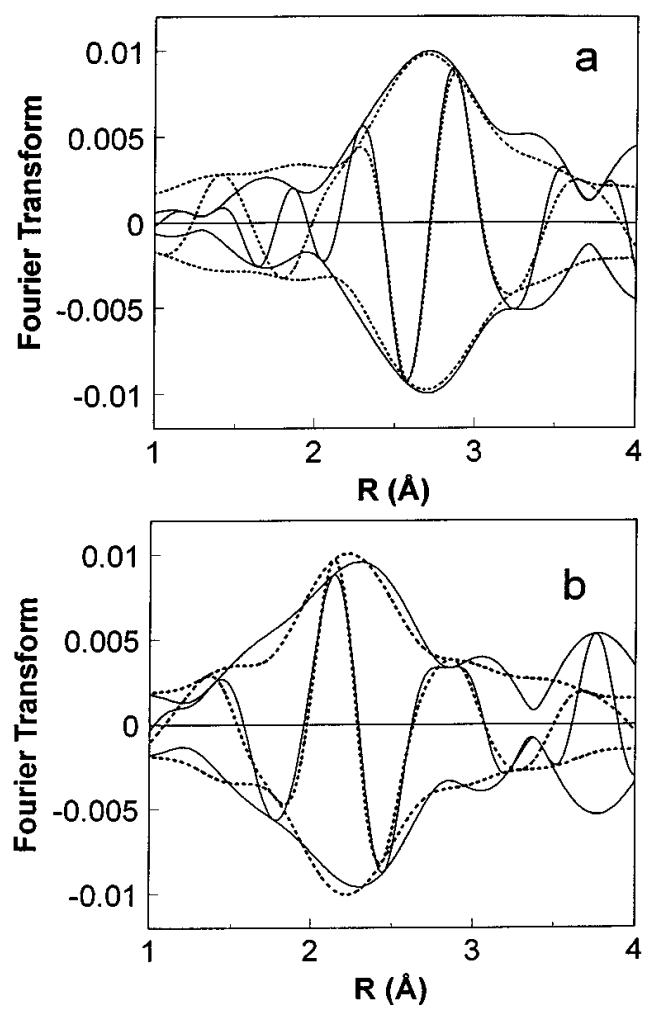

FIG. 7. The Fourier transform $\left(\mathrm{k}^{1}, \Delta \mathrm{k}=3.5-13.5 \mathrm{~A}^{-1} \mathrm{Pt}-\mathrm{O}\right.$ phase corrected) of the (EXAFS data- (Pt-Pt + Pt-S contributions)) (solid line) and the model fit of the Pt-O contribution (dotted line) calculated from the parameters in Table 2. (a) Pt/H -LTL and (b) Pt(S)/H -LTL. 

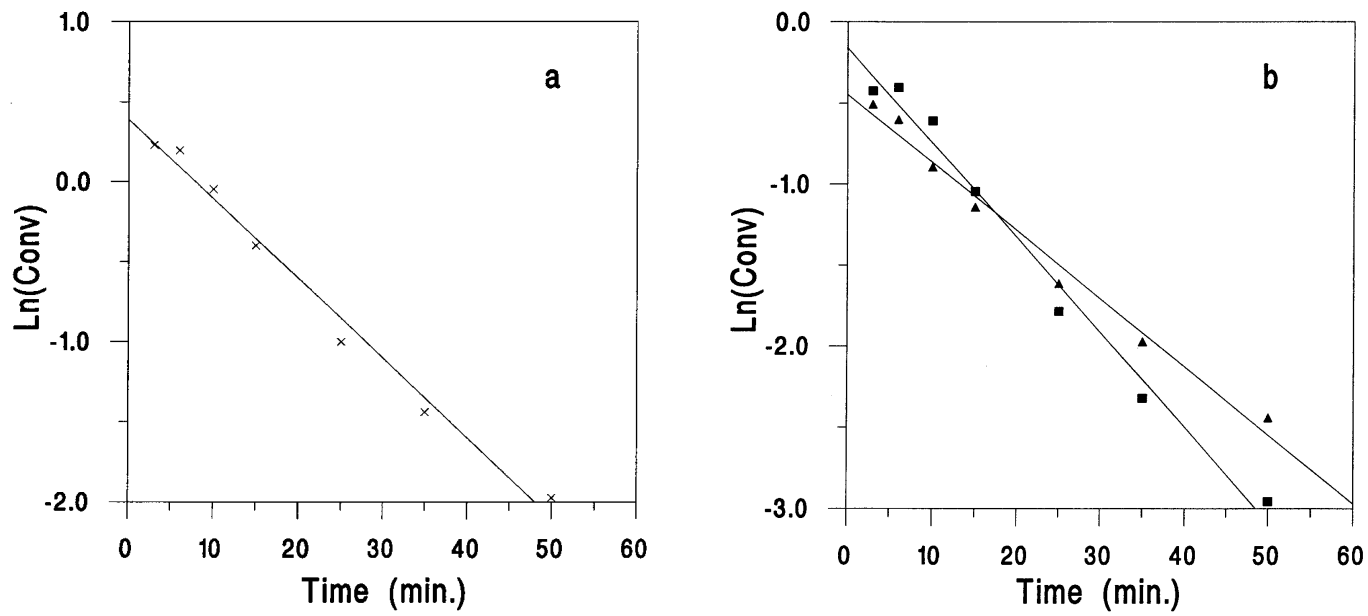

FIG. 8. Catalyst deactivation of neopentane ( $1 \%$ neopentane in $\mathrm{H}_{2}$, atmospheric pressure, $400^{\circ} \mathrm{C}$ ) for $\mathrm{Pt}(\mathrm{S}) / \mathrm{K}$-LTL . (a) Total conversion $(x)$, and (b) hydrogenolysis (square), and isomerization (triangle). Solid lines are model fits to data ( Conv $_{\mathrm{t}}=\mathrm{Conv}_{0} * \mathrm{e}^{-\mathrm{kt}}$ ).

about 0.01 molecules/s/surface Pt. The loss in activity due to sulfur poisoning, therefore, primarily results from the physical blockage of the platinum surface. A sobserved with other sulfur poisoned metal catalysts $(6,8,35,36)$, the hydrogenolysis selectivity decreases from 0.61 in Pt/K -LTL to 0.48 in $\mathrm{Pt}(\mathrm{S}) / \mathrm{K}-\mathrm{LTL}$, or the isomerization selectivity increases from 0.39 to 0.52 .

Sulfur poisoning of $\mathrm{Pt} / \mathrm{H}-\mathrm{LTL}$ also leads to a large decrease in activity per gram of catalytst. For example, the relative activity/gram in $\mathrm{Pt} / \mathrm{H}-\mathrm{LTL}$ is 55 times higher than that in $\mathrm{Pt} / \mathrm{K}-\mathrm{LTL}$, and decreases to 2 times higher in $\mathrm{Pt}(\mathrm{S}) / \mathrm{H}-\mathrm{LTL}$. It should be noted that the activity per gram of the sulfur poisoned $\mathrm{Pt} / \mathrm{H}-\mathrm{LTL}$ is still higher than the activity sulfur-free Pt/K-LTL (relative activity of 1.0). A s observed for $\mathrm{Pt}(\mathrm{S}) / \mathrm{K}-\mathrm{LTL}$, the TOF is nearly the same as the sulfur-free catalysts, and the isomerization selectivity increases from 0.35 in Pt/H -LT to 0.80 in Pt(S)/H -LTL.

A Iso given in Table 3 are the deactivation rate constants based on the equation

$$
\operatorname{Conv}_{t}=\operatorname{Conv}_{0} * e^{-k t}
$$

In the equation, Conv is the total neopentane conversion $\left(\right.$ Conv $_{\mathrm{t}}=$ conversion at time on stream, Conv $_{0}=$ conversion at zero time on stream) and $\mathrm{k}$ is the deactivation rate constant with time measured in minutes. The space velocity was adjusted to give an initial conversion of $1 \%$ for each catalyst. The deactivation rate for each catalyst is shown in Fig. 9. As discussed above, the deactivation of $\mathrm{Pt} / \mathrm{H}-\mathrm{LTL}$ is much higher than Pt/K -LTL. U pon poisoning of Pt/K-LTL by sulfur, the deactivation rate constant increases from $6 \times 10^{-4}$ to $5 \times 10^{-2} \mathrm{~min}^{-1}$, an increase of about 100 times. In $\mathrm{Pt}(\mathrm{S}) / \mathrm{H}-\mathrm{LTL}$, however, there is almost no deactivation, while there is a rapid loss in activity for sulfur free Pt/H -LTL.

\section{DISCUSSION}

Structural Characterization

The EXA FS analysis shows that for both the Pt/H -LTL and the Pt/K -LTL small platinum clusters are present. From the Pt-Pt coordination numbers, the number of platinum atoms/cluster can be estimated to be about 5 to 7 atoms for

TABLE 3

Activity, Selectivity and D eactivation R ate for $\mathrm{N}$ eopentane $\mathrm{H}$ ydrogenolysis ${ }^{a}$

\begin{tabular}{|c|c|c|c|c|c|}
\hline Catalyst & $\begin{array}{l}\text { R elative activity } \\
\text { (per g catalyst) }\end{array}$ & $\begin{array}{l}\text { TOF } \\
\left(\mathrm{H}_{2}\right)\end{array}$ & $\begin{array}{l}\text { TOF } \\
(\mathrm{CO})\end{array}$ & $\begin{array}{l}\text { Isomerization } \\
\text { selectivity }^{\mathrm{b}}\end{array}$ & $\begin{array}{l}\text { D eactivation rate } \\
\text { constant }\left(\mathrm{min}^{-1}\right)\end{array}$ \\
\hline Pt/H -LTL (0.46) & 55 & 0.9 & 1.5 & 0.35 & $2 \times 10^{-2}$ \\
\hline $\mathrm{Pt}(\mathrm{S}) / \mathrm{H}-\mathrm{LTL}$ & 1.8 & 2.5 & 2.1 & 0.80 & $6 \times 10^{-4}$ \\
\hline Pt/K -LTL (1.19) & $1.0^{c}$ & 0.01 & 0.01 & 0.39 & $6 \times 10^{-4}$ \\
\hline $\mathrm{Pt}(\mathrm{S}) / \mathrm{K}-\mathrm{LTL}$ & 0.09 & 0.02 & 0.01 & 0.52 & $5 \times 10^{-2}$ \\
\hline
\end{tabular}

a $D$ etermined at $400^{\circ} \mathrm{C}$ and $1 \mathrm{~atm}, 1 \%$ neopentane in $\mathrm{H}_{2}$.

${ }^{b}$ Extrapolated to $0 \%$ conversion and deactivation.

${ }^{\mathrm{C}} \mathrm{D}$ efined to have a relative activity of $1.0 / \mathrm{g}$ catalyst. 


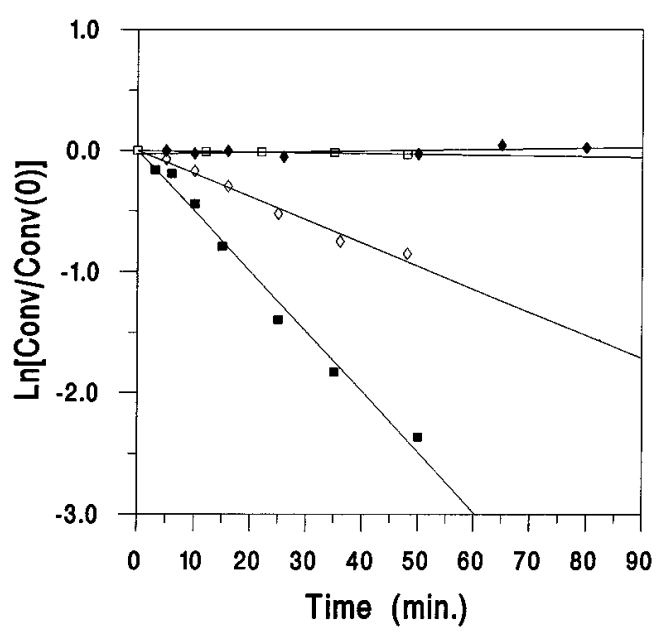

FIG. 9. Catalyst deactivation in the total conversion of neopentane ( $1 \%$ neopentane in $\mathrm{H}_{2}$, atmospheric pressure, $400^{\circ} \mathrm{C}$ ) for $\mathrm{Pt} / \mathrm{H}-\mathrm{LTL}$ (open diamond), Pt/K -LTL (open square), Pt(S)/H -LTL (closed diamond) and $\mathrm{Pt}(\mathrm{S}) / \mathrm{K}-\mathrm{LTL}$ (closed square). The solid lines are model fits to data $\left(\right.$ Conv $_{\mathrm{t}}=$ Conv $\left._{0} * \mathrm{e}^{-\mathrm{kt}}\right)$, and the initial conversions were $1 \%$.

Pt/K -LTL and 12 to 15 for Pt/H -LTL. Catalysts with similar EXAFS Pt-Pt coordination numbers and prepared by the same procedure leads to platinum clusters within the pores as evidenced by electron microscopy $(29,37)$. The Pt-Pt bond distance in the metallic clusters is $2.74 \AA^{\circ}, 0.03 \AA^{\circ}$ smaller than in Pt foil. A decrease of the metal-metal coordination distance can be expected when going from bulk metal to very small metal particles since the electron density in small particles is more localized on the metal atom, effectively shielding the internuclear replusion $(38,39)$. In a vacumn, a decrease in the metal-metal bond distance of approximately $0.1 \mathrm{~A}^{\circ}$ has been observed for small metal particles, e.g., $\mathrm{Pt} / \gamma-\mathrm{A} \mathrm{I}_{2} \mathrm{O}_{3}$ (40), $\mathrm{Pt} / \mathrm{Y}$ (41), and $\mathrm{r} / \gamma-\mathrm{A} \mathrm{I}_{2} \mathrm{O}_{3}$ (42). By contrast, bulk-like coordination distances are observed for small metal particles covered by chemisorbed hydrogen $(28,29,40,42)$. Chemisorbed hydrogen withdraws electron density from the metal atom which increases the internuclear repulsions and results in an expansion of the metalmetal bond distance. For the sulfur-free catalysts of this study, the platinum particles are so small that the contraction in the bond distance is not fully compensated by the expansion induced by chemisorbed hydrogen.

B ecause of the small size of the platinum clusters in both catalysts, oxygen ions from the support can be detected. Since the platinum particles are smaller in $\mathrm{Pt} / \mathrm{K}-\mathrm{LTL}$ than $\mathrm{Pt} / \mathrm{H}-\mathrm{LTL}$, there is a larger fraction of the platinum atoms in contact with the support which is consistant with the larger Pt- 0 coordination number, e.g., $\mathrm{N}=0.9$ for Pt/K -LT L compared to $\mathrm{N}=0.5$ for $\mathrm{Pt} / \mathrm{H}-\mathrm{LTL}$. The observed Pt-O distance around $2.7 \AA$ is characteristic of platinum catalysts reduced at low temperature and is longer than the sum of the atomic radii for platinum and oxygen. This long distance results from the presence of chemisorbed hydrogen between the metal cluster and the support surface $(28,30,31)$.

Severe sulfur poisioning of zeolite supported platinum clusters does not destroy the metallic properties. For both $\mathrm{Pt}(\mathrm{S}) / \mathrm{H}-\mathrm{LTL}$ and $\mathrm{Pt}(\mathrm{S}) / \mathrm{K}-\mathrm{LTL}$, the Pt-Pt bond distance is $2.71 \AA^{\circ}$ characteristic of metallic Pt $\left(2.77 \AA^{\circ}\right)$ and much shorter than the Pt-Pt distance in bulk PtS ( $3.47 \mathrm{~A}^{\circ}$ ) or bulk $\mathrm{PtS}_{2}\left(3.54 \mathrm{~A}^{\circ}\right.$ ) (43). Similar Pt-Pt distances have been previously observed in sulfur poisoned Pt/Ba-KLTL (44) and PtNi/K -LTL (45). Sulfur is chemisorbed on the outer surface of the metallic platinum particle with a Pt-S distance of $2.32 \mathrm{~A}^{\circ}$. The $\mathrm{Pt}-\mathrm{S}$ distance is similar to that in bulk PtS $\left(2.31 \AA^{\circ}\right)$, but shorter than that in $\mathrm{PtS}_{2}\left(2.40 \AA^{\circ}\right)(43)$. A similar Pt-S structure, i.e., surface adsorbed sulfur on metallic platinum particles, with the same bond distance of $2.3 \mathrm{~A}$ was previously reported for Pt/B a-K LTL sulfur poisoned at $500^{\circ} \mathrm{C}$ (44). Sulfur poisoning also results in a decrease in the Pt-Pt bond distance and coordination number and an increase in disorder, compared to the unsulfided catalysts. For example, a Pt-Pt distance of $2.71 \mathrm{~A}^{\circ}$ is $0.03 \mathrm{~A}^{\circ}$ shorter than that in the sulfur-free catalysts and $0.06 \AA^{\circ}$ shorter than that in Pt foil. A s discussed above, a contraction of the platinum bond distance is expected because of the small particle size. A t the same time, chemisorption of both hydrogen and sulfur would be expected to increase the Pt-Pt bond distance. In the sulfur poisoned catalysts, the hydrogen chemisorption capacity is very low (approximately $5 \%$ of the sulfurfree catalyst) due to the blockage of the surface atoms by sulfur. A s a result, the expansion of the metal bond distance associated with chemisorbed hydrogen is small. The effect of chemisorbed sulfur, therefore, is not sufficient to fully compensate for the contraction of the bond distance in these small, surface-sulfide metal particles.

A lthough the decrease in bond distance suggests there is an increase in the Pt-Pt bond strength, in these platinum particles the number of nearest neighbors is very much smaller than is the bulk. A s a result, the cohesive energy per Pt atom is smaller than in the bulk (36), resulting in a larger disorder in the sulfur poisoned catalysts.

Sulfur poisoning also leads to a slight decrease in Pt-Pt coordination number. A lthough this could be interpreted as a decrease in the metal particle size, it is not likely that at the low sulfiding temperatures that the platinum particles would be disrupted and that individual atoms would diffuse across the catalyst surface to form new, smaller platinum clusters. I t seems more likely that upon sulfidation there is a small reorientation of the atoms leading to a small al teration in the particle morphology. In such a model, the number of atoms per clusters is unchanged, but there is a decrease in the number of nearest neighbor platinum atoms. Previous studies of sulfur poisoning of Pt in LTL zeolite at $500^{\circ} \mathrm{C}$ indicated that platinum particles increased in size, filling the zeolite pores $(44,46)$. By contrast, formation of bimetallic PtNi particles in K-LTL were resistant to sintering 
by sulfur (45). At the lower temperatures of this study $\left(250^{\circ} \mathrm{C}\right)$, sulfur does not appear to lead to sintering of the Pt particles.

In addition to changes in the structure of the platinum particles, sulfur adsorption induces changes in the structure of the metal-support interface. For example, after sulfur poisoning the Pt-O distance is $2.2 \mathrm{~A}^{\circ}$, compared to $2.7 \mathrm{~A}^{\circ}$ in the sulfur-free catalysts. This shorter distance is characteristic of zero-valent metal atoms in direct contact with the oxide of the support $(28,31)$ and is typically observed after high temperature reduction (24), or evacuation after low temperature reduction (42). B ecause sulfidation and reduction were conducted at low temperature, the change in the Pt-O distance cannot be explained by thermal desorption of interfacial hydrogen (28). The low hydrogen chemisorption capacity of the sulfur poisoned suggests that platinum atoms with sulfur neighbors are unable to chemisorb hydrogen. It is possible that platinum atoms in contact with support oxygen ions, which additionally chemisorb sulfur, are unable to stabilize interfacial hydrogen resulting in a short $\mathrm{Pt}-\mathrm{O}$ distance in $\mathrm{Pt}(\mathrm{S}) / \mathrm{H}-\mathrm{LTL}$ and $\mathrm{Pt}(\mathrm{S}) / \mathrm{K}-\mathrm{LTL}$.

The EXAFS structural analysis show that the metalsulfide phase is identical in Pt(S)/H -LTL and Pt(S)/K -LTL, differing only in the metal particle size, sulfur coordination, etc. D espite the structural similarities there is significantly less sulfur per surface platinum atom in the acidic supported catalyst. B ased on the Pt-S coordination numbers and the small metal particle size of these catalysts, the ratio of sulfur to platinum surface atoms is approximately one for $\mathrm{Pt}(\mathrm{S}) / \mathrm{H}-\mathrm{LTL}$ and two for Pt(S)/K -LTL .

\section{Catalytic Properties}

As previously observed for benzene hydrogenation $(47,48)$, propane hydrogenolysis $(34,49)$, and hydrogenolysis and isomerization of neopentane (30,33, 34, 50-52), the TOF for neopentane conversion is higher for platinum on acidic zeolite, i.e., Pt/H -LTL as compared to alkaline Pt/ $\mathrm{K}$-LTL. For similar $P d / L T L$ catalysts this rate enhancement was shown to be due to a change in the electronic properties of the Pd induced by the support. For example, the PdX -ray photoelectron spectra (XPS) showed an increase in the $3 d$ binding energy of $0.6 \mathrm{eV}$ for $\mathrm{Pd} / \mathrm{H}-\mathrm{LTL}$ and a decrease in binding enegy of $-0.8 \mathrm{eV}$ for $\mathrm{Pd} / \mathrm{K}-\mathrm{LTL}$, compared to $\mathrm{Pd}$ foil, indicating the acidic-supported $P d$ is electron-deficient and the alkaline-supported Pd is electron-rich, compared to Pd foil. Furthermore, these shifts in the XPS binding energies were correlated with the changes in the neopentane and propane hydrogenolysis TO Fs, indicating that the differences in the electronic properties are responsible for the observed changes in the specific rates. A dditional evidence for a change in the electronic properties on these $\mathrm{Pd}$ catalysts was obtained from infrared spectroscopy. For both linear and bridge bonded $\mathrm{CO}$, there is a decrease in the vibrational frequency as the alkalinity of the support increases. A the same time, a decrease in the ratio of linear to bridge bonded $\mathrm{CO}$ occurs as the alkalinity of the support increases; this is also consistent with an increase in the electron density of Pd on alkaline LTL (50). Similar shifts to lower frequency in the infrared spectra of the linear and bridge bonded $\mathrm{CO}$ are observed for Pt/LTL, again indicating a modification of the metal electronic properties by the support. A the same time as observed for $\mathrm{Pd}$, there is a continual shift from linear to bridge bonded $\mathrm{CO}$ as the alkalinity of the support increases. Furthermore, this decrease in the ratio of linear to bridge bonded $\mathrm{CO}$ correlates with the decrease in the specific rate for neopentane hydrogenolysis of $\mathrm{Pt}$, indicating that these changes in electronic properties induced by the supports are responsible for theses changes in specific activity (54). From the studies above, we conclude that the much higher TOF of Pt/H -LTL is due to the electron defficient nature of Pt on acidic $H-L T L$.

The activity per gram of catalyst of both sulfur-poisoned catalysts is much lower, approximately 5-10\%, than that of the sulfur-free catalyst. B ecause of the much higher intrinsic activity of the $P t / H-L T L$, even after sulfur poisoning, the activity per gram of $\mathrm{Pt}(\mathrm{S}) / \mathrm{H}-\mathrm{LTL}$ is still higher than that of sulfur-free Pt/K -LTL. A Ithough there is a large decrease in the per gram activity, the TOF of the sulfur-poisoned catalysts is nearly identical to that of the sulfur-free catalysts. The small differences in TOF between the sulfur-free and sulfur-poisoned catalysts likely results from the error in the chemisorption determination for the sulfur-poisoned catalysts which are very low. B ecause the TOF of the sulfurpoisoned and sulfur-free catalysts are essentially identical, the effect of adsorbed sulfur is primarily due to physical blockage of the surface platinum atoms. This implies that chemisorption of sulfur is not changing the electronic properties of the metal particle.

In addition to a decrease in the activity (per gram) of the sulfur poisoned catalysts, there is an increase in the isomerization selectivity. A structure-sensitive reaction like hydrogenolysis requires a larger ensemble of platinum atoms than isomerization $(55,56)$. B ecause of the high surface coverage of platinum by sulfur in both $\mathrm{Pt}(\mathrm{S}) / \mathrm{H}-\mathrm{LTL}$ and $\mathrm{Pt}(\mathrm{S}) / \mathrm{K}-\mathrm{LTL}$, it is likely that the remaining, active platinum atoms are more isolated than in the sulfur-free catalysts. The lower hydrogenolysis selectivity of the sulfur-poisoned catalysts is consistant with a smaller ensenble size in the sulfided metal particles. L ower hydrogenolysis selectivties have been observed for other sulfur poisoned catalysts $(6,8,35,36)$.

A Ithough the structure of the platinum-sulfur phase and the large effect of sulfur on the decrease in activity is identical for both acidic and alkaline supported platinum, the rate of deactivation by coke is much lower in the Pt(S)/H -LTL than in $\mathrm{Pt}(\mathrm{S}) / \mathrm{K}-\mathrm{LTL}$. From the EXAFS it was shown that 
the sulfur coverage is much higher in $\mathrm{Pt}(\mathrm{S}) / \mathrm{K}-\mathrm{LTL}$, perhaps, with most of the sulfur-free platinum atoms completely isolated from other sulfur-free platinum surface sites. We propose that these isolated sites are not capable of simultaneous reaction with neopentane and hydrogen. Thus, these hydrogen deficient sites rapidly coke. A Ithough the initial specific activity of $\mathrm{Pt}(\mathrm{S}) / \mathrm{K}-\mathrm{LTL}$ is identical to that of sulfurfree $P t / K-L T L$, the former does not maintain this activity due to coke formation. In Pt(S)/H-LTL, the lower sulfur coverage results in larger platinum ensembles which provide enough hydrogen to prevent rapid deactivation.

The deactivation rate of $\mathrm{Pt}(\mathrm{S}) / \mathrm{H}-\mathrm{LTL}$ is also lower than that in sulfur-free Pt/H -LTL. G enerally, coke deactivation of platinum during the conversion of neopentane is thought to result from adsorption of olefin intermediates (isobutylene and isopentene) on support acid sites. Since olefins react rapidly with the strong $B$ ronsted acid sites in zeolites at the reaction conditions, it is likely that the olefin intermediates form coke at support sites near, or perhaps adjacent to, the platinum particles. These coke deposits would eventually decrease the platinum availability, leading to a loss in activity. B ecause of the high sulfur coverage of platinum in $\mathrm{Pt}(\mathrm{S}) / \mathrm{H}-\mathrm{LTL}$, fewer active platinum atoms may be near support acid sites. Thus, the amount of coke formed near the platinum-sulfur clusters is low. M ore work, however, is required to fully understand the low deactivation rate of the sulfur poisoned acidic supported platinum. R egardless of the reason, the low deactivation rate in $\mathrm{Pt}(\mathrm{S}) / \mathrm{H}-\mathrm{LTL}$ is essential for maintenance of the activity in sulfur tolerant noble metal catalysts.

\section{CONCLUSION}

On acidic LTL zeolite, the specific rate of platinum for neopentane hydrogenolysis and isomerization is nearly 100 times higher than that on alkaline LTL. This enhanced rate is due to the interaction of the metal particles with the acidic support producing electron deficient platinum. B oth acidic and alkaline supported platinum catalysts irreversibly loose much of their (sulfur free) activity when exposed to sulfur. Exposure of the small metallic particles to $\mathrm{H}_{2} \mathrm{~S}$, results in the formation of surface Pt-S bonds. Simultaneously, there is a decrease in the Pt-Pt bond distance, a loss of interfacial hydrogen and a slight change in the particle morphology. B ecause of the much higher specific activity of acidic supported platinum, even after sulfur poisoning the activity per gram is still higher than that of sulfur free, alkaline supported platinum. D espite the large loss in the per-gram activity of both sulfur poisoned catalysts, the intrinsic activity of the remaining surface platinum atoms in the sulfur poisoned clusters is identical to that in the sulfur-free platinum clusters. The primary effect of adsorbed sulfur is due to the loss of active sites by physical blockage. A Ithough platinum on acidic and alkaline supported LTL zeolite both irreversibly adsorb sulfur, the sufrace coverage ( $\mathrm{S}$ to $\mathrm{Pt}$ ratio) is lower in acidic supported catalyst. B ecause of the high suface coverage of Pt in alkaline LTL, the active sites are more nearly isolated and are rapidly deactivated by coke. Sulfur tolerance of noble metals on acidic supports, therefore, results from their higher specific rate and their resistance to coke deactivation.

\section{REFERENCES}

1. "Oil and G as Journal D ata B ook", Penn Well, Tulsa, 1994.

2. B artholomew, C. H ., A grawal, P. K., and K atzer, J. R ., A dv. Catal. 31, 135 (1982).

3. B arbier, J., L amy-Pitara, E ., M arecot, P., B oitiaux, J. P., Cosyns, J., and Verna, F., A dv. Catal. 37, 279 (1990).

4. Buss, W. C., Field, L. A ., and R obinson, L. C., U.S. Patent N $0.4,456,526$ (1984).

5. H ughes, T. R ., B uss, W. C., Tamm, P. W., and Jacobson, R . L., in "Stud. in Surf. Sci. and Catal. 28, Proc. 7th Int. Zeolite Conf." (Y. M urakami, A . Iijima, and J. W. Ward, Eds.), p. 725, Elsevier Sci., A msterdam, 1986.

6. Menon, P. G., and Prasad, J., "Proceedings, 6 Int. Cong. Catal." (G. C. B ond, P. B. Wells, and F. C. Tomkins, Eds.), Vol. 2, p. 1061 Chem. Soc., L ondon, 1977.

7. G ates, B. C., K atzer, J. R ., and Schuit, G. C. A ., "Chemistry of Catalytic Processes," p. 190, M CG raw-H ill, N ew Y ork, 1979.

8. Bickle, G. M., Biswas, J., and D o, D. D., A ppl. Catal. 36, 259 (1988).

9. M inderhoud, J. K ., and L ucien, J. P., E uropean Patent N o. 303,332, "A Process for $\mathrm{H}$ ydrogenation of Hydrocarbon Oils."

10. Kukes, S. G., Clark, F. T., and H opkins, P. D., U.S. Patent N 0. 5,147,426, "Distillate $\mathrm{H}$ ydrogenation."

11. Kukes, S. G., Clark, F. T., H opkins, P. D., and G reen, L. M ., U.S. Patent N o. 5,151,172, "D istillate H ydrogenation."

12. van den B erg, J. P., L ucien, J. P., G ermaine, G., and Thielemans, G. L. B., Fuel Proc. Technol. 35, 119 (1993).

13. R abo, J. A ., Shomaker, V., and Pickert, P. E ., in "Proceedings, 3rd Int. Cong. Catal." (W. M. H. Sachtler, G. C. A . Schuit, and P. Z wietering, E ds.), Vol. 2, p. 1264, N orth-H olland, A msterdam, 1965.

14. Chukin, G. D., Landau, M. V., K ruglikov, V. Y., A gievskii, D. A ., Smirnov, B. V., B elozerov, A . L., A srieva, V. D., Goncharova, N. V., Radchenko, E. D., Konoval'chikov, O. D., and A gafonov, A. V., in "Proceedings, 6 Int. Cong. Catal." (G. C. B ond, P. B. Wells and F. C. Tomkins, E ds.), Vol. 2, p. 1264, Chem. Soc., London, 1977.

15. Landau, M. V., K ruglikov, V. Y., G oncharova, N. V., Konoval'chikov, O. D., Chukin, G. D., Smirnov, B. V., and M alevich, V. I., K inet. Catal. 17, 1104 (1976).

16. Kovach, S. M., and K mecak, R. A ., Prepr. A m. Chem. Soc. Div. Pet. Chem. 25(1), 79 (1980).

17. Frety, R ., D a Silva, P. N., and G uenin, M ., Catal. L ett. 3, 9 (1989).

18. Frety, R., D a Silva, P. N., and Guenin, M., A ppl. Catal. 57, 99 (1990).

19. H oyos, L. J., Primet, M ., and Praliaud, H., J. Chem. Soc. Faraday Trans. 88, 113 (1992).

20. M arecot, P., M ahoungou, J. R ., and B arbier, A ppl. Catal. A G en. 101, 143 (1993).

21. K ampers, F. W. H., M ass, T. M . J., van G rondelle, J., B rinkgreve, P., and Koningsberger, D. C., Rev. Sci. Instr. 60, 2645 (1989).

22. Vaarkamp, M ., D ring, I., O Idman, R . J., Stern, E. A ., K oningsberger, D. C., Phys. Rev. B 50, 7872 (1994).

23. Cook, J. W., J r., and Sayers, D. E., J. A ppl. Phys. 52, 5024 (1981).

24. Kampers, F. W. H., Engelen, C. W. R., Van Hooff, J. H. C., and Koningsberger, D. C., J. P hys. Chem. 94, 8574 (1990).

25. Koningsberger, D. C., in "Physics and Chemistry of Solids. Hercules Course" (J. B aruchel, J. L. H oudeau, M. S. Lehmann, J. R. R egnard, and C. Schlenker, E ds.), Vol. II, p. 213, Springer-Verlag, B erlin, 1993. 
26. D uivenvoorden, F. B. M., Koningsberger, D. C., U h, Y. S., and G ates, B. C., J. A m. Chem. Soc. 108, 6254 (1986).

27. Lytle, F. W., Sayers, D. E., and Stern, E. A., Physica B 158, 701 (1989).

28. Vaarkamp, M., M odica, F. S., M iller, J. T., and Koningsberger, D. C., J. Catal. 144, 611 (1993).

29. M iller, J. T., Sajkowski, D. J., M odica, F. S., L ane, G. S., G ates, B. C., Vaarkamp, M., G rondelle, J. V., and Koningsberger, D. C., Catal. L ett. 6, 369 (1990).

30. M iller, J. T., M eyers, B. L., M odica, F. S., Lane, G. S., Vaarkamp, M., and Koningsberger, J. Catal. 143, 395 (1993).

31. Koningsberger, D. C., Vaarkamp, M ., M unoz Paez, A ., and van Zon, F. B. M., in " $X$-ray A bsorption Fine Structure (XA FS) for Catalysis and Surfaces" (Y. I wasawa, E d.), to be published.

32. Bhore, N. A ., K lein, M. T., and B ischoff, Ind. Eng. Chem. Res. 29, 313 (1990).

33. M odica, F. S., M iller, J. T., M eyers, B. L., and Koningsberger, D. C., Catal. Today 21, 37 (1994).

34. M ojet, B. L., K appers, M. J., M uijsers, J. C., N iemantsverdriet, J. W., M iller, J. T., M odica, F. S., and Koningsberger, D. C., in "Stud. in Surf. Sci. and Catal., 84B, Z eolites and M icroporous M aterials: State of the A rt 1994" (J. Weitkamp, H.G. Karge, H. Pfeifer and W. Holderich, Eds.), p. 909, Elsevier Sci., A msterdam, 1994.

35. Menon, P. G., M arin, G. B., and Froment, G. F., Ind. Eng. Chem. Prod. Res. D ev. 21, 52 (1982).

36. Coughlin, R. W., Hasan, A., and Kawakami, K., J. Catal. 88, 163 (1984).

37. L ane, G. S., M odica, F. S., and M iller, J. T., J. Catal. 129, 145 (1991).

38. D elly, B., Ellis, D. E., Freeman, A. J., Baerends, E. J., and Post, D., Prys. Rev. B 27, 2132 (1983).

39. Balerna, A ., and M obilio, S., Prys. Rev. B 34, 2293 (1986).

40. Vaarkamp, M., thesis, "The Structure and Catalytic Properties of Supported Platinum Catalysts," E inhoven U niversity of Technology, The Netherlands, 1993.

41. M oraweck, B., G lugnet, G., and R enouprez, A . J., Surf. Sci. 81, L 631 (1979).
42. K ampers, F. W. H ., and Koningsberger, D. C., Faraday D iscuss. Chem. Soc. 89, 137 (1990).

43. G ronvold, F., H araldsen, H ., and K jekshus, A ., A cta Chem. Scand. 14, 1879 (1960).

44. Vaarkamp, M., Miller, J. T., Modica, F. S., Lane, G. S., and Koningsberger, D. C., J. Catal. 138, 675 (1992).

45. Larsen, G., R essasco, D. E ., D urante, V. A ., K im, J., and H aller, G. L., in "Stud. in Surf. Sci. and Catal., 83, Z eolites and M icroporous Crystals" (T. H attori, and T. Y ashima, E ds.), p. 321, Kodansha, Toyko and E Isevier, A msterdam, 1994.

46. M cV icker, G. B., K ao, J. L., Ziemiak, J. J., G ates, W. E ., R obbins, J. L., Treacy, M. M. J., Rice, S. B., Vanderspurt, T. H., Cross, V. R ., and G hosh, A. K., J. Catal. 139, 48 (1993).

47. Figueras, F., Gomez, R ., and Primet, M ., in "M olecular Sieves," A dv. Chem. Ser. Vol. 121 (W. M. M eier and J. B. U ytterhoeven, E ds.), p. 480, A CS, Washington, D C, 1973.

48. Lin, S. D., and Vanice, M. A ., J. Catal. 143, 539 (1993).

49. Vaarkamp, M., Miller, J. T., Modica, F. S., Lane, G. S., and Koningsberger, D. C., in "Stud. in Surf. Sci. and Catal., 75A, N ew Frontiers in Catalysis" (L. G uczi, F. Solymosi, and P. Tetenyi, E ds.), p. 809, E Isevier, A msterdam, 1993.

50. H oymeyer, S. T., K arpinski, Z., and Sachtler, W. M. H ., J. Catal. 123, 60 (1990).

51. Karpinski, Z., G andhi, S. N., and Sachtler, W. M . H ., J. Catal. 141, 337 (1993).

52. Larsen, G., and H aller, G. L., Catal. Today 15, 431 (1992).

53. van Santen, R. A ., J. Chem. Soc. Faraday Trans. I 83, 1915 (1987).

54. M ojet, B. L., K appers, M. J., M iller, J. T., and Koningsberger, D. C., in "Stud. in Surf. Sci. and Catal., 101, Procs. 11th Int. Cong. of Catal." (J. W. H ightower, W. N. D elgass, E. I glesia, and A. T. B ell., E ds.), p. 1165, E Isevier, A msterdam, 1996.

55. Frennet, A ., Lienard, G., Crucq, A ., and D egols, L., J. Catal. 53, 150 (1978).

56. B oudart, M., and D ejega-M ariadassou, G., "K inetics of H eterogeneous Catalytic Reactions" (J. M. Prausnitz and L. Brewer, E ds.), p. 173, Princeton U niv. Press, Princton, N J, 1984. 